but finally Clarke came up with an ending. There is no indication that either of them ever knew what it meant, or cared very much one way or the other. "I don't like to talk about 2001", said Kubrick; "I don't pretend we have the answers", said Clarke.

Clarke later wrote a succession of sequels and other 'last books', and one might suppose that How the World Was One: Beyond the Global Village is one of them. But in truth it's mostly an early book repackaged. Although it is not mentioned anywhere on the dust jacket, How the World Was One is largely a revision of Clarke's book Voice Across the Sea, first published in 1958. The rest consists of addresses given on various occasions, three previously published short stories and, for good measure, the two scientific papers in which Clarke proposed the idea of communications satellites. Not that there is anything wrong with an author's recycling of old materials - just so long as the prospective buyer is informed of the fact beforehand. Notwithstanding that there are fewer than 50 pages of new material here, Clarke has described How the World Was One as "My longest book .... It may also be one of my most important, since it's covering the whole history of telecommunications, from the invention of the telegraph, up to the fibre optic revolution."

The whole history is indeed there, and the first part of the story, dealing with the laying of the transatlantic cable, makes exciting reading. "Wiring the abyss", as Clarke puts it, was one of those impractical utopian fantasies that everyone knew could never be realized. Often enough it seemed that way even to the participants, chief among whom were Cyrus W. Field, who financed the project, and Isambard Kingdom Brunel, who built the ship, the Great Eastern, that laid the cable. Much of their tale is cliffhanging stuff. The first attempt to lay the cable, in 1857 , met with failure when the cable snapped and was lost after 335 miles had been paid out. The second try, in 1858 , was successful for a three-week period, after which the line went dead. The third try, in 1865 , went well until the cable parted in the middle of the ocean and dropped to the bottom. Incredibly, the broken end was snagged by a grappling hook and was almost retrieved, but at the surface the rope broke and the whole mess slipped back to the ocean floor, two miles below, where it was not found again for several months.

The rest of the book, unfortunately, is not nearly so compelling, describing how a gaggle of communications satellites were lofted into orbit on a series of anonymous rockets. Instantaneous global communication is now something that we take so much for granted that the story has lost its lustre.

One may wonder, then, why Clarke is still so entranced by it. His answer, made clear in the text time and again, is his belief that instantaneous global communication is the royal road to peace among men. Satellite talk will make the world 'One', turning us into the Big Global Village, the Planetary Happy Family. This, though, is a delusion. Whereas Clarke's hope is that communications satellites will promote "understanding", the fact is that they will promote whatever messages are bounced off them, and it is just as easy to send orders to assassinate a leader or wipe out a village as it is to bring tidings of universal peace and brotherhood. Nowhere was this better illustrated than during the Gulf War, instantaneous live coverage of which Clarke portrays as showing us "the true horrors of modern mechanised war". On the contrary, what it showed us were absolutely thrilling images of 'smart' bombs homing in on and destroying office buildings - images that were in large part responsible for making this one of the most popular wars in American history.

As for the idea that One World means unity and peace, sufficient disproof is offered by the existence of civil wars, which have been some of the bloodiest ever fought on the planet. Anyone who thinks that One World (or One Nation or One Anything Else) will bring us peace and harmony should spend a few silent moments contemplating the gravestones at Gettysburg Battlefield, where during the American Civil War some 51,000 casualties were sustained in three days.

Ed Regis is at Western Maryland College, Westminster, Maryland 21157, USA.

\title{
Physicist in the shadows
}

\section{Hermann Bondi}

The Recollections of Eugene Wigner as Told to Andrew Szanton. By Andrew Szanton. Plenum: 1992. Pp. 335. $\$ 24.50$.

HAVING as its subject a man who is not only an outstanding physicist, but also most unusual and indeed idiosyncratic in his attitudes and outlook, this volume should have been superb and gripping, yet in fact it does not generally rise to these heights. Perhaps Andrew Szanton was too self-effacing and too little of the probing professional interviewer who would have coaxed more out of his subject. But then, if he had taken such an approach, Wigner might not have talked to him at all. We should therefore all be grateful to Szanton, because this book is likely to remain the most we will ever know about a fascinating person. It deserves to be read by all with even a modest interest in the personalities who shaped modern quantum physics.

Despite my little gripe, much of the book is absorbing. The early chapters about Wigner's home life and upbringing are thorough and accordingly riveting. Especially moving are his feelings about his school, his teachers in general and his mathematics teacher in particular. Nobody who reads these chapters can have any doubts that an outstanding teacher can deeply influence and foster the abilities of able pupils who without such a stimulus might never rise to great heights of achievement, whatever their innate abilities. How much talent is undiscovered, unstimulated, unfostered in our world? This is a worrying, sobering thought generated by these chapters.

The life of a Jewish professional family in Hungary in those far-off days comes over well, but I was perturbed by confusion in the text about what was Austro-Hungarian and what was Hungarian in the days of the Dual Monarchy, a matter that is likely to disturb other readers less than me. But the brief paragraph on how such a civilized and humane family could come to terms with living under the blood-stained Horthy regime is superb. I recall only too well how dreadful it looked from Austria.

Although the description of the chain of circumstances that made Wigner a physicist against the wishes of his father makes excellent reading, the account of the rest of these years of apprenticeship is too brief and too scrappy. One hungers for more about the giants of the time and their interaction, but one is given only brief vignettes. Illuminating flashes occur and are a delight. To hear that Dirac's work was found difficult because he wrote in English gives one a healthy shock. For few recall now how dominant German was as the language of science for a period that Hitler brought to a sharp end. It would make a good study to analyse how the language of Newton, Faraday and Maxwell came to be quite secondary to German for some decades before it acquired its present dominance. But again, although there are splendid shafts of light describing Dirac's unique attitude to conversation, one would have hoped to hear more about an extraordinary man who was not only Wigner's friend and colleague but also his brother-in-law. But 
the biggest problems in these sections about the pre-war period are due to Wigner's obtrusive modesty. The overly shy description of what he did in those years gives no clue that it was work of Nobel-prize calibre.

The book really comes alive again with the chapters dealing with Wigner's involvement in the Manhattan Project. These are quite excellent. They will be particularly appreciated by all those unacquainted with the workings of bureaucracy, especially if they can sense how much it can eventually achieve. The remarks about General Groves are splendid, as are the sketches of Fermi and other scientists. Wigner is a little less self-effacing about his own contribution here, but even so I would have liked to learn more about it. On the other hand, Wigner's ruminations about the work that was going on in Germany on the atomic bomb are generous and thought-provoking, as are his revealing comments on Oppenheimer.

The post-war period is described in an illuminating way. Wigner could come to terms with a bureaucracy driven by the pressures of war, but not with one in peacetime. The return to Princeton was a success, which enabled him to do much external work in which he evidently found some satisfaction and some frustration. He is at his most engagingly frank when talking about the Nobel prize and the pleasure it gave him.

Perhaps the most revealing paragraphs relate to his fellow Hungarians Szilard, von Neumann and Teller. His tortured love-hate relationship with Szilard evidently troubled him greatly, and the honesty of his remarks is transparent. His admiration for von Neumann and his grief for his early death come through very well, but inevitably it is his comments on that very controversial character, Teller, that hold most interest. Wigner's loyalty to Teller is total, but he manages to combine it with his admiration for Oppenheimer's leadership at Los Alamos in a frank and indeed engaging manner. What informed Wigner's Hungarian group was a permanent deep hatred of communism (perhaps because of the experience of Bela Kun?), never ameliorated by the slim hope that so many of us entertained for so many years that something less obnoxious, even if still ostensibly communist, might eventually emerge in Eastern Europe.

This brief description cannot possibly do justice to an important and very worthwhile book. My disappointments, which I have expressed freely, should not discourage anybody from reading it. In the interests of science I wish this book every success.

Sir Hermann Bondi is at Churchill College, Cambridge CD3 ODS, UK.

\section{From thought to expression}

\section{S. S. Schweber}

Genius: Richard Feynman and Modern Physics. By James Gleick. Pantheon/ Little, Brown: 1992. Pp. 532. \$27.50, £18.99.

SCIENTIFIC communities usually seek to convey the importance and the history of their discipline through the lives of their outstanding practitioners - individuals whose very creativity renders them unlikely to be the best representatives of their worlds. Physicists have principally chosen theorists as their heroic figures (Newton, Maxwell, Einstein, Planck, Bohr, Dirac, Pauli) or experimenters who left their mark in both experimenta-

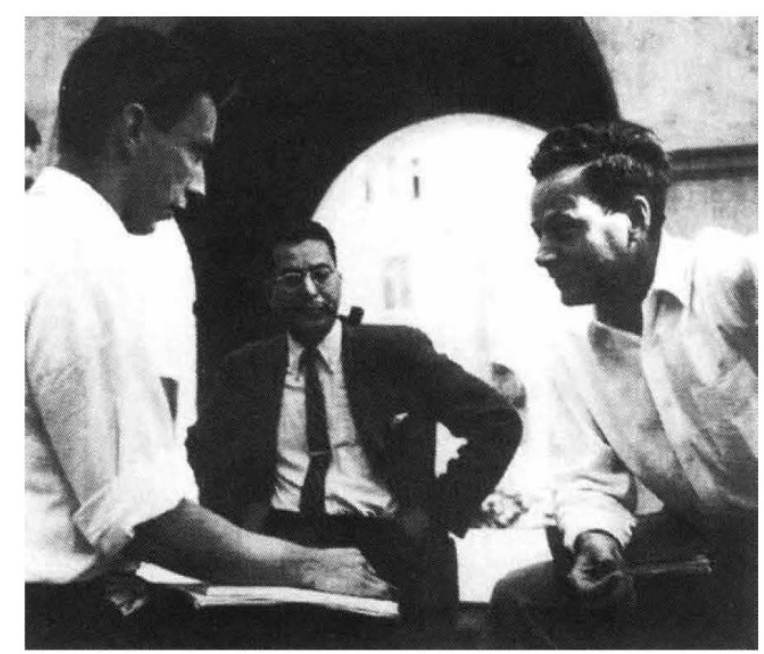

Talking it through - Feynman chats with a student as Murray Gell-Mann looks on.

tion and theory (J. J. Thomson, Rutherford, Fermi), thereby emphasizing the ties of the discipline to the tradition of natural philosophy. The cult idols are the reification of the aspirations and myths of the community and the embodiments of its cherished values. (And just as what is not said can be as revealing as what is, those left out of the hall of fame disclose much about the community.)

Einstein and Bohr, and to a lesser degree Planck and Rutherford, are the heroes from the period before the Second World War. They have come to stand for the advances ushered in by relativity and quantum mechanics. Dirac embodies the 'genius' of the quantummechanical revolution and is the prophet who pointed the way in the synthesis of relativity and quantum mechanics. And Landau and Feynman have become the heroes of the post-quantummechanical era. Both were enormously creative and innovative and made lasting conceptual contributions (a necessary condition for admission to the pantheon). Both encompassed all of physics, and could therefore be taken as representing the unity of the enterprise, resisting the fragmentation of the discipline and the attendant specialization. Although at various times they set and dominated the intellectual agenda of the community, they were often also the main challengers of the ruling orthodoxies. They were thus simultaneously insiders and outsiders. Similarly, both were unusual in their social behaviour - and the community was willing to condone in them conduct that would not be acceptable in society at large. And after the Second World War, during an epoch shaped by the Cold War, polarized by concerns about national security and dominated by military-industrial complexes, both men consciously distanced themselves from the conflict. They could therefore be seen as 'pure scientists' transcending national rivalries.

There is so far no satisfactory intellectual and psychological portrait of Landau or an adequate account of his life. But with James Gleick's Genius we now have a superb biography of Feynman. The book is a moving, beautifully written, literate and perceptive account of Feynman's life, which Gleick sets sensitively in the context of the physics community, of the larger culture and of the times.

We get a feel for life in the Jewish community of Far Rockaway during the 1920 s. We learn what it was like to be an undergraduate at the Massachusetts Institute of Technology during the 1930s. We become privy to the extensive antisemitism in the élite American universities at that time; to life at Los Alamos during the Second World War; to the politics of universities after the war; to the dynamics of selecting and receiving Nobel prizes; to the world of NASA stripped of its public-relations gloss, and the behind-the-scenes activities of the presidential commission investigating the Challenger disaster.

As readers of Gleick's earlier book Chaos know, this author has a gift for capturing the atmosphere of a community and for providing sharply focused, perceptive sketches of its principal characters. We get to know Schwinger, Bethe, Weisskopf, Dyson, Gell-Mann and some of the other leading theorists, and, while doing so, we learn a great deal about the sociology of the theoretical physics community of the time and 